\title{
Anti-inflammatory properties of ebselen in a model of sephadex-induced lung inflammation
}

\author{
M.G. Belvisi, E-B. Haddad, C. Battram, M. Birrell, M. Foster, S. Webber
}

\begin{abstract}
Anti-inflammatory properties of ebselen in a model of sephadex-induced lung inflammation. M.G. Belvisi, E-B. Haddad, C. Battram, M. Birrell, M. Foster, S. Webber. (C) ERS Journals Ltd 2000.

ABSTRACT: Ebselen (2-phenyl-1,2-benzisoselenazol-3(2H)-one), is a seleno-organic compound which protects tissues against oxidative stress. Furthermore, recent data has suggested that this compound possesses a range of anti-inflammatory properties.

In this study the authors have investigated the effects of ebselen on Sephadexinduced lung oedema and bronchoalveolar lavage (BAL) tumour necrosis factor (TNF)- $\alpha$ and endothelin(ET)-1 levels in rats.

Sephadex administration induced lung oedema which was accompanied by an increase in BAL TNF- $\alpha$ and ET-1 levels. Ebselen administration (1-30 $\mathrm{mg} \cdot \mathrm{kg}^{-1}$, i.p. at 0,4 and $12 \mathrm{~h}$ post Sephadex) significantly inhibited lung oedema (dose that produced $50 \%$ of the maximum inhibition of lung oedema $4.6 \mathrm{mg} \cdot \mathrm{kg}^{-1}$ ) and BAL TNF- $\alpha$ levels in a dose-related manner with no effect on ET-1 levels.

These data suggest that ebselen may be a useful therapy in lung pathologies in which bronchiolar inflammation is a feature.

Eur Respir J 2000; 15: 579-581.
\end{abstract}

The Sephadex model of lung oedema in the rat is a model of acute alveolitis and bronchiolitis leading to inflammatory cell infiltration and interstitial oedema which appears to parallel many of the pathophysiological features associated with human interstitial lung diseases [1]. This model has been used previously to demonstrate the anti-inflammatory properties of compounds such as glucocorticosteroids based upon the modulation of lung oedema [2].

Ebselen (2-phenyl-1,2-benzisoselenazol-3 (2H)-one) is a selenium-containing organic compound which has been found to protect tissue against oxidative attack by mimicking glutathione peroxidase and phospholipid hydroperoxide glutathione peroxidase [3]. In addition, ebselen possesses a range of anti-inflammatory activities including inhibition of the enzymes 5-lipoxygenase, inducible nitric oxide synthase, reduced nicotinamide adenine dinucleotide phosphate (NADPH) oxidase and inactivation of leukotriene $\mathrm{B}_{4}$ to its biologically inactive 6-trans isomer [4]. In view of its interesting anti-inflammatory profile in a variety of animal models of inflammation $[1,5]$, the authors investigated its effects in the Sephadex model of lung oedema. In addition, the effect of ebselen was examined on tumour necrosis factor (TNF)- $\alpha$ and endothelin(ET)-1 levels in the bronchoalveolar lavage (BAL) fluid from Sephadex-treated rats since these cytokines have been postulated to have a role in inflammatory lung disease [6-9].

\section{Animals \\ Materials and methods}

Male, Sprague-Dawley rats (350 g) were purchased from Harlan-Olac (Bicester, Oxfordshire, UK) and housed for 1 week before initiating experiments. Food and water were supplied ad libitum. Experiments were performed in accordance with the UK Home Office guidelines for ani- mal welfare based on the Animals (Scientific Procedures) Act 1986 [10] and following approval from the Aventis Pharma Animal Care and Use Committee.

\section{Methods}

Rats were dosed intratracheally (i.t.) with vehicle (saline) or Sephadex beads $\left(5 \mathrm{mg} \cdot \mathrm{kg}^{-1}\right)$ in a dose volume of 1 $\mathrm{mL} \cdot \mathrm{kg}^{-1}$ under halothane anaesthesia $(4 \%$ in oxygen for 3 min). Ebselen (1-30 mg. $\left.\mathrm{kg}^{-1}\right)$ or vehicle (25\% dimethyl sulfoxide (DMSO), 75\% polyethylene glycol (PEG) 200) was administered intraperitoneally (i.p.) following Sephadex administration $(0 \mathrm{~h})$ and then at 4 and $12 \mathrm{~h}$ post Sephadex in a dose volume of $0.5 \mathrm{~mL} \cdot \mathrm{kg}^{-1}$. The dosing regimen was determined from a previous study [1] which demonstrated preliminary data describing the inhibitory activity of a single dose of ebselen $\left(10 \mathrm{mg} \cdot \mathrm{kg}^{-1}\right.$, i.p. $)$ on sephadex-induced lung oedema.

\section{Measurement of lung oedema}

Rats were sacrificed $24 \mathrm{~h}$ post-sephadex with Euthatal (1 $\mathrm{mL} \cdot \mathrm{kg}^{-1}, i . p$.), the heart and lungs removed en bloc, and the lung wet weights determined and expressed per $100 \mathrm{~g}$ initial body weight. Percentage inhibition of oedema (Sephadex i.t./vehicle i.p. control) was then determined for each treatment group. A dose-response curve was generated, a sigmoidal fit obtained for the data and the dose that produced $50 \%$ of the maximum inhibition of lung oedema (ED50) was calculated.

Measurement of cytokine production in the bronchoalveolar lavage fluid

Rats were sacrificed $24 \mathrm{~h}$ post-Sephadex with Euthatal $\left(1 \mathrm{~mL} \cdot \mathrm{kg}^{-1}\right.$, i.p. $)$ and lavaged (for $30 \mathrm{~s}$ at room temperature) 
at $1 \mathrm{~mL} \cdot \mathrm{kg}^{-1}$ body weight with Roswell Park Memorial Institute medium (RPMI)/glutamate plus $10 \%$ foetal calf serum (FCS). This was repeated once and the two samples pooled. The BAL fluid sample was then centrifuged at 800 $\times g$ for 10 min and the supernatant frozen for later analysis. BAL fluid interleukin(IL)-1 $\beta$, TNF- $\alpha$ and ET-1 levels were determined by enzyme linked immunosorbent assay (ELISA).

Euthatal and Halothane were obtained from Rhône Mérieux (Harlow, Essex, UK) and RPMI from GIBCO, (Paisley, Strathclyde, Scotland, UK), Sephadex G-200 was purchased from Pharmacia (Uppsala, Sweden). DMSO and PEG 200 were purchased from Sigma (Poole, Dorset, UK). Ebselen (2-phenyl-1,2-benzisoelenazol-3(2H)-one) was synthesized by the Chemistry Department of RhônePoulenc Rorer (Vitry, France). Rat IL- $1 \beta$ and TNF- $\alpha$ ELISA kits were purchased from Life Screen Ltd (Watford, UK) and Genzyme (West Malling, UK), respectively. Human ET-1 ELISA kits were purchased from R\&D Systems (Abingdon, UK).

\section{Analysis}

All values presented are mean \pm SEM from $n=8$ rats per group. The percentage inhibition of oedema (compared to the Sephadex administered, vehicle-treated group) was determined for each Ebselen-treated group. The dose-response curve for inhibition of lung oedema by Ebselen was calculated by least squares, nonlinear iterative regression with the "PRISM" curve fitting programme (Graphpad Instat software programme, San Diego, CA, USA). An ED50 value was subsequently interpolated from a curve of best fit. The data were analysed using the Kruskal-Wallis nonparametric test with a correction for multiple comparison's using Dunnett's critical values. A p-value of less than 0.05 was considered to be statistically significant.

\section{Results}

\section{Lung oedema}

Sephadex instillation alone evoked a significant oedema, $38.5 \%(p<0.01)$, which was reduced to $26.3 \%$ in vehicle-treated animals. This inhibition of oedema in the vehicle-treated group was not significant. Ebselen evoked a dose-dependent inhibition of lung oedema (ED50 of 4.6 $\mathrm{mg} \cdot \mathrm{kg}^{-1}$ ) when compared to lung wet weights from Sephadex instilled, vehicle-treated animals (fig. 1).

\section{Cytokine production in the bronchoalveolar lavage flu- id}

There were no detectable levels of IL-1 $\beta$, TNF- $\alpha$ or ET1 in the vehicle treated group. There were no detectable levels of IL-1 $\beta$ in BAL from Sephadex-treated rats but there was a significant increase in BAL TNF- $\alpha$ (fig. 2) and ET-1 levels (vehicle treated group, $0.043 \pm 0.02 \mathrm{pg} \cdot \mathrm{mL}^{-1}$; Sephadex-treated group, $1.35 \pm 0.29 \mathrm{pg} \cdot \mathrm{mL}^{-1}, \mathrm{p}<0.001$ ) compared to the vehicle-treated group. Ebselen dosedependently reduced BAL TNF- $\alpha$ levels when compared to the Sephadex/vehicle control group. This effect was significant at 10 and $30 \mathrm{mg} \cdot \mathrm{kg}^{-1}$ (fig. 2). ET-1 levels were not altered by ebselen $\left(0.3-30 \mathrm{mg} \cdot \mathrm{kg}^{-1}\right)$.

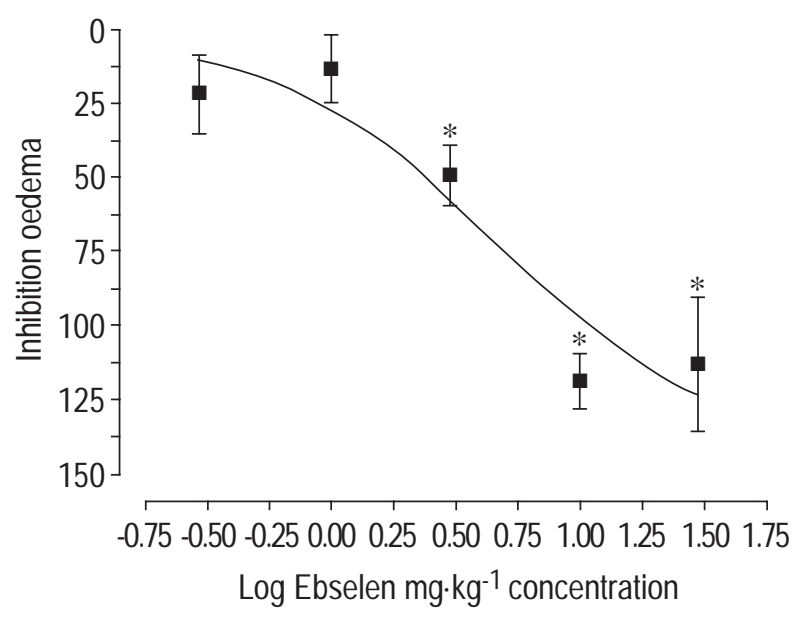

Fig. 1. - Inhibitory effect of ebselen $\left(0.3-30 \mathrm{mg} \cdot \mathrm{kg}^{-1}\right.$, administered immediately after Sephadex instillation and then at 4 and $12 \mathrm{~h}$ post Sephadex, i.p. on Sephadex-induced lung oedema in the rat. Points represent mean \pm SEM of eight rats.

\section{Discussion}

In this study the authors have investigated the effect of ebselen on Sephadex-induced lung oedema and BAL TNF- $\alpha$ levels. Sephadex particles induce lung oedema $24 \mathrm{~h}$ post-instillation. This effect was completely inhibited in a dose-dependent fashion by ebselen with an ED50 of 4.6 $\mathrm{mg} \cdot \mathrm{kg}^{-1}$ and confirms previous preliminary findings [1] in which CotgReave et al. [1] demonstrated 98\% inhibition of Sephadex-induced lung oedema at a single dose of 10 $\mathrm{mg} \cdot \mathrm{kg}^{-1}$. The data presented here takes these observations further by establishing that the inhibitory effect of ebselen is dose-related. In addition, the authors have determined the potency and maximal efficacy of this compound and attempted to elucidate the mechanism of action of ebselen in this model.

In addition, the authors investigated the effect of ebselen on TNF- $\alpha$ levels in the BAL fluid from Sephadex-treated rats since this cytokine has been postulated to have a role in

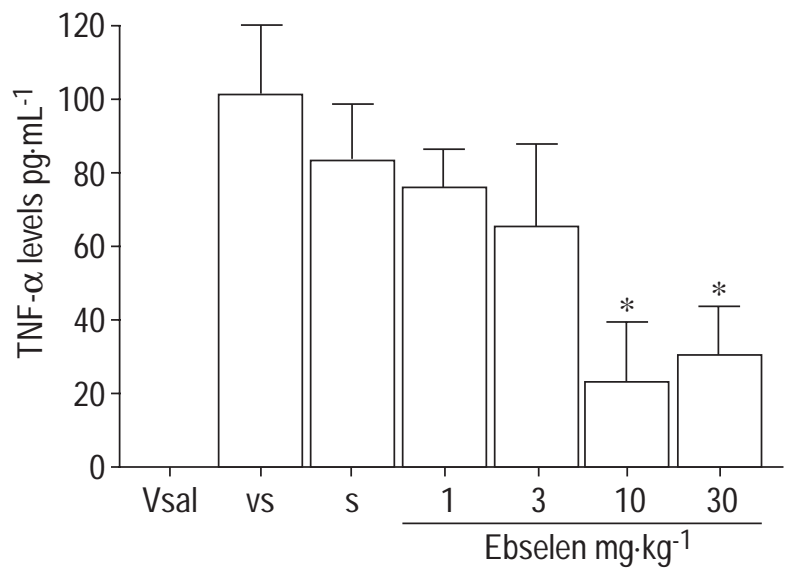

Fig. 2. - Effect of ebselen (1-30 $\left.\mathrm{mg} \cdot \mathrm{kg}^{-1}\right)$ on Sephadex-induced tumour necrosis factor (TNF)- $\alpha$ levels in bronchoalveolar lavage (BAL) fluid. The effects of vehicle on saline (Vsal)- and sephadex(vs)-induced TNF$\alpha$ levels as well as the effect of sephadex alone (s) on TNF- $\alpha$ levels in BAL fluid are also shown. BAL fluid supernatants were assayed for TNF- $\alpha$ levels by enzyme linked immunosorbent assay (ELISA). Data are mean \pm SEM of eight rats. 
an animal model of antigen-induced oedema [10] and in inflammatory lung disease [6]. Indeed, TNF- $\alpha$ levels are increased in several inflammatory diseases including asthma and chronic obstructive pulmonary diseases [7, 11]. It has also previously been demonstrated that Sephadex particles increase TNF- $\alpha$ messenger ribonucleic acid (mRNA) and protein expression in lung epithelial cells, lung granulomas and BAL cells [12]. Interestingly, IL- $1 \beta$ and TNF- $\alpha$ have been shown to induce an increase in prepro-ET-1 mRNA and ET-1 peptide expression in cultured pulmonary endothelial cells of rats [13]. In addition, Sephadex instillation evokes an increase in ET in the BAL fluid and the mixed ETA/B receptor antagonist, Bosentan, inhibits the cellular inflammatory response elicited by Sephadex [14]. In this study the authors have explored the hypothesis that Sephadex increases the expression of TNF- $\alpha$ leading to an increase in ET-1 levels which is involved in the production of Sephadex-induced lung oedema. However, the data presented demonstrate that ebselen dose-dependently reduced TNF$\alpha$, but not ET-1, levels in the BAL fluid of Sephadextreated rats. These data suggest that the anti-inflammatory action of ebselen may be due to its inhibitory action on TNF- $\alpha$ release and that the increased levels of ET- 1 follwing Sephadex instillation are not associated with the production of Sephadex-induced lung oedema.

Cotgreave et al. [1] have also demonstrated that ebselen inhibits infiltration of eosinophils, lymphocytes and basophils into the airway lumen in response to Sephadex whilst leaving the macrophage and neutrophil populations largely unchanged. This profile of biological activity would appear to be ideal for a compound targeted at treating lung inflammatory diseases as ebselen possesses the required anti-inflammatory activity whilst allowing continued protection of the lung from opportunistic infections by the presence of macrophages and neutrophils.

In conclusion, these data demonstrate that ebselen possesses anti-inflammatory activity in this rat model of lung inflammation which may be related to inhibition of tumour necrosis factor- $\alpha$ production. These results also suggest that this drug may be useful in a range of lung pathologies in which bronchiolar inflammation is a feature.

\begin{abstract}
Acknowledgements. The authors would like to acknowledge D. Hele, K. McCluskie and A. Ling
\end{abstract} for technical assistance.

\section{References}

1. Cotgreave IA, Johansson U, Westergren G, Moldeus PW,
Brattsand R. The anti-inflammatory activity of Ebselen but not thiols in experimental alveolitis and bronchiolitis. Agents Actions 1988; 24: 313-319.

2. Källstrom L, Brattsand R, Lövgren U, Svensjö E, Roempke K. A rat model for testing anti-inflammatory action in lung and the effect of glucocorticosteroids (CGS) in this model. Agents Actions 1985; 17: 355-357.

3. Sies H. Ebselen, a selenoorganic compound as glutathione peroxide mimic. Free Radical Biol Med 1993; 14: 313-323.

4. Parnham M. The pharmaceutical potential of seleno-organic compounds. Exp Opin Invest Drugs 1996; 5: 861870.

5. Wendel A, Tiegs G. A novel biologically active selenoorganic compound VI. Protection by ebselen (PZ51) against glactosamine/endotoxin-induced hepatitis in mice. Biochem Pharmacol 1986; 35: 2115-2118.

6. Ying S, Robinson DS, Varney V, et al. TNF- $\alpha$ mRNA expression in allergic inflammation. Clin Exp Allergy 1991; 21: 745-750.

7. Gosset P, Tsicopoulos A, Wallaert B, et al. Increased secretion of tumor necrosis factor $\alpha$ and interleukin- 6 by alveolar macrophages consecutive to the development of the late asthmatic reaction. J Allergy Clin Immunol 1991; 88: 561-571.

8. Redington AE, Springall DR, Ghatei A, et al. Endothelin bronchoalveolar lavage fluid and its relation to airflow obstruction in asthma. Am J Respir Crit Care Med 1995; 151: 1034-1039.

9. Springall DR, Howarth PH, Counihan H, Djukanovic S, Holgate ST, Polak JM. Endothelin immunoreactivity of airway epithelium in asthmatic patients. Lancet 1991; 337: 697-70.

10. Renzetti LM, Paciorek PM, Tannu SA, et al. Pharmacological evidence for tumour necrosis factor as a mediator of allergic inflammation in the airways. J Pharmacol Exp Ther 1996; 278: 847-853.

11. Barnes PJ. New therapies for chronic obstructive pulmonary disease. Thorax 1998; 53: 137-147.

12. Williams CMM, Smith L, Flanagan BF, Clegg LS, Coleman JW. Tumour necrosis factor- $\alpha$ expression and cell recruitment in Sephadex particle-induced lung inflammation: effects of dexamethasone and cyclosporin A. $\mathrm{BrJ}$ Pharmacol 1997; 122: 1127-1134.

13. Golden CL, Kohler HS, Nick HS, Visner GA. Effects of vasoactive and inflammatory mediators on endothelin-1 expression in pulmonary endothelial cells. Am J Respir Cell Mol Biol 1995; 22: 503-512.

14. Finsnes F, Skønsberg OH, Tønnessen T, Næss O, Lyberg T, Christensen G. Endothelin production and effects of endothelin antagonism during experimental airway inflammation. Am J Respir Crit Care Med 1997; 155: 1404-1412. 